\title{
Modeling of consequences of hypothetical accidental radioactive contamination of gulfs and bays in Murmansk region of Russian Federation
}

\author{
A.L. Krylov and O.A. Pavlovski \\ Nuclear Safety Institute Russian Academy of Sciences, Russia
}

\begin{abstract}
At present at coasts of Northwest region of Russian Federation there are sites of storage and decommissioning of retired nuclear submarines, their nuclear reactors, spent nuclear fuel and radioactive waste. Some of those sites are not isolated. There is a hazard of release of radioactivity from those sites that can lead to contamination of vast neighborhood areas. The Nuclear Safety Institute of Russian Academy of Sciences has developed the computer model of dispersion of radioactivity in the seas gulfs and bays.
\end{abstract}

\section{INTRODUCTION}

At present at coasts of Northwest region of Russian Federation there are sites of storage and decommissioning of retired nuclear submarines, their nuclear reactors, spent nuclear fuel and radioactive waste. Some of those sites are not isolated. There is a hazard of release of radioactivity from those sites that can lead to contamination of vast neighborhood areas. This was the reason of implementing of the project "Improvement of the Murmansk region system of radiation monitoring and emergency response" (Project). Under the Project two crisis centers was created. The crisis centers was equipped by software for assessment of consequences of possible release of radioactivity. The Nuclear Safety Institute of Russian Academy of Sciences is the main executor of the Project [1]. In the frame of the Project the Institute has developed the computer model of dispersion of radioactivity in the gulfs and bays.

\section{DESCRIPTION OF THE MODEL}

The model is based on well-known Princeton Ocean Model (POM) - three-dimensional primitive equation model that enables calculation of velocity fields and transport of mass, heat and salinity [2]. The POM is distributed as free computer code and documentation.

The mathematical model on which POM is based enables taking into account all significant processes and factors that affect velocity fields. The influence of pressure gradients, viscosity, Coriolis force and solar radiation is included to the governing equations. The bottom friction is taken into account with the use of boundary conditions. Evaporation, inflow of fresh water, wind forcing and tide-induced currents can also be taken into account with the use of boundary conditions.

The surface of the water is considered free. The pressure gradients are mainly the result of the gradients of water salinity, temperature and level of free water surface. That's why the POM model enables modeling of transport of heat and salinity. The model is based on the three-dimensional equation of convection and diffusion.

But for the gulfs and bays that are important for the Project the main external processes affecting the velocity fields is wind and tidal forcing. The pressure gradients are not so important because of relatively cold climate in the region, absence of major rivers that flow into the gulfs and bays of interest, and absence of stable (warm or cold) currents in the gulfs and bays. 
The Nuclear Safety Institute has added to the POM code the model of transport of radioactive contaminants. The model is based on the three-dimensional equation of convection and diffusion the same as so as for the salinity. The sorption of the radioactive contaminants on the suspended particles and sedimentation of the particles are not taken into account. The reasons are the following:

- The time of modeling is considered to be of magnitude of several days after a hypothetical accident.

This time is less or equal to characteristic time of sorption of radioactive substances on suspended particles and sedimentation of the particles. It is supposed that during this time the necessary countermeasures (if any) will be implemented and thorough control on the water contamination levels will be established.

- The inaccessibility of detailed data make difficult developing detailed and reliable model taking into account the migration of radioactivity on suspended particles.

- The neglect of the migration on suspended particles results in "conservative" assessment of amount of radioactive contaminants leaving a bay (over evaluation). i.e. real contamination of the Barents Sea will be lower than assessed by the model.

As it was mentioned above, for calculation of velocity fields it is necessary to model tides. The model of tides taking into account the 21 fundamental harmonics was developed on the base of [3] and included into the computer code and successfully validated against tide tables at the Yekateriniskaya Bay [4]. This Bay is located in the same region. The level of tides is the same in the region. The phase displacement of tidal cycles between different bays of interest in the region is of magnitude of several minutes. Thus this model of tides can be used to set open boundary conditions for all of the important bays of Barents Sea in the Murmansk region.

Supplementary the model of tides was successfully checked by comparison of predicted tides (Harwich, UK) with tides predicted by [5].

\section{VALIDATION OF THE MODEL}

The testing of the model has been done by analysis of results of modeling of consequences of hypothetical accident at the temporary storage facility of reactor units at Saida Bay. Saida Bay is located in the Murmansk region of Russian Federation. It is part of Kola Bay of Barents Sea. Computational grid of Saida bay is shown at Fig. 1.
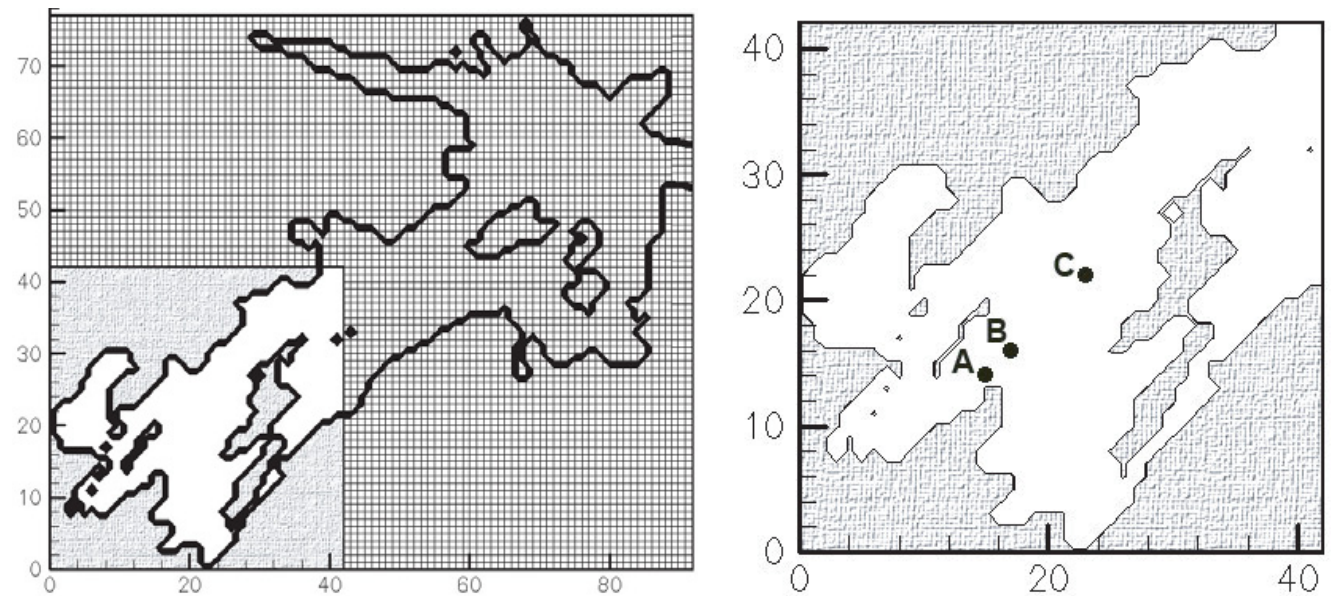

Figure 1. Left: computational grid used for modeling. Right: A - point of hypothetical accidental release of radioactivity; B, C - points of reference (see Fig. 3). 
The size of the region of modeling region is about $5,6 \mathrm{~km}$ from east to west $\times 5,1 \mathrm{~km}$ from south to north. The uniform computational grid with 89 steps $(63 \mathrm{~m}$ each) from east to west, 77 steps $(66 \mathrm{~m}$ each) from south to north was used. In vertical direction was used non-uniform sigma coordinate computational grid with 7 steps from water surface to bottom. When using sigma coordinate grid, the number of steps is constant throughout the region of modeling but the magnitude of one step is proportional to the water column height in specific location.

It has been done calculations for hypothetical accident taking place at difference phases of tidal cycle, at different weather conditions (wind speed and direction, etc). The velocity fields and spatial distribution of radioactivity were calculated for time of 24 hours after the accident (see Fig. 2).

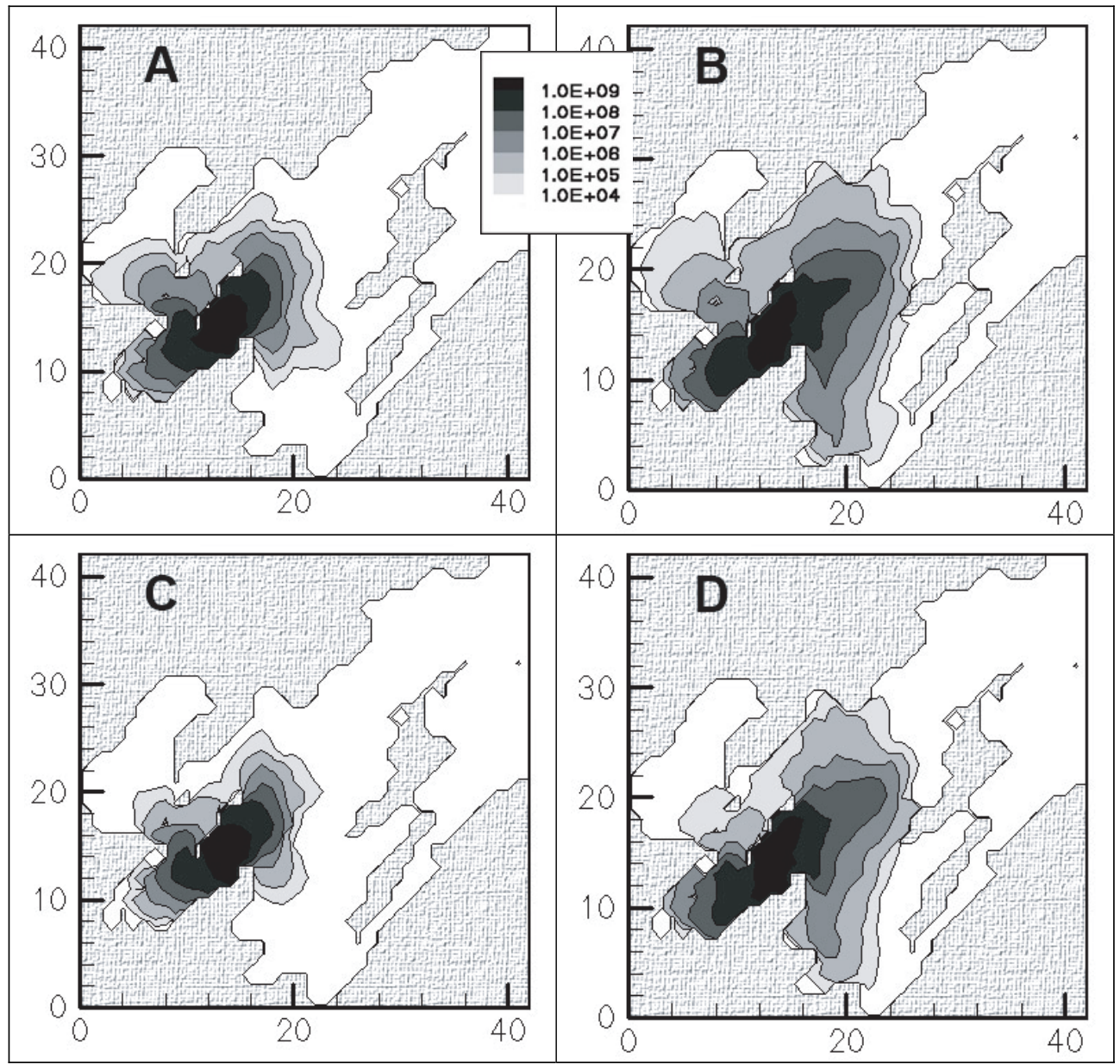

Figure 2. Calculated contamination of surface layer of water of Saida bay in 24 hours after the hypothetical accident: A - accident at the moment of high water (no wind); B - accident at the moment of high water (wind from the south $10 \mathrm{~m} / \mathrm{s}$ ); $\mathrm{C}$ - accident at the moment of low water (no wind); D - accident at the moment of low water (wind from the south $10 \mathrm{~m} / \mathrm{s}$ ).

The calculations have shown that contaminated area in 24 hours after the hypothetical accident is situated in the south-west part of the Bay for any wind and any phase of the tide in the moment of the hypothetical accident. Thus only this southwest part of the Saida Bay was selected for future analysis (see Fig. 1). 

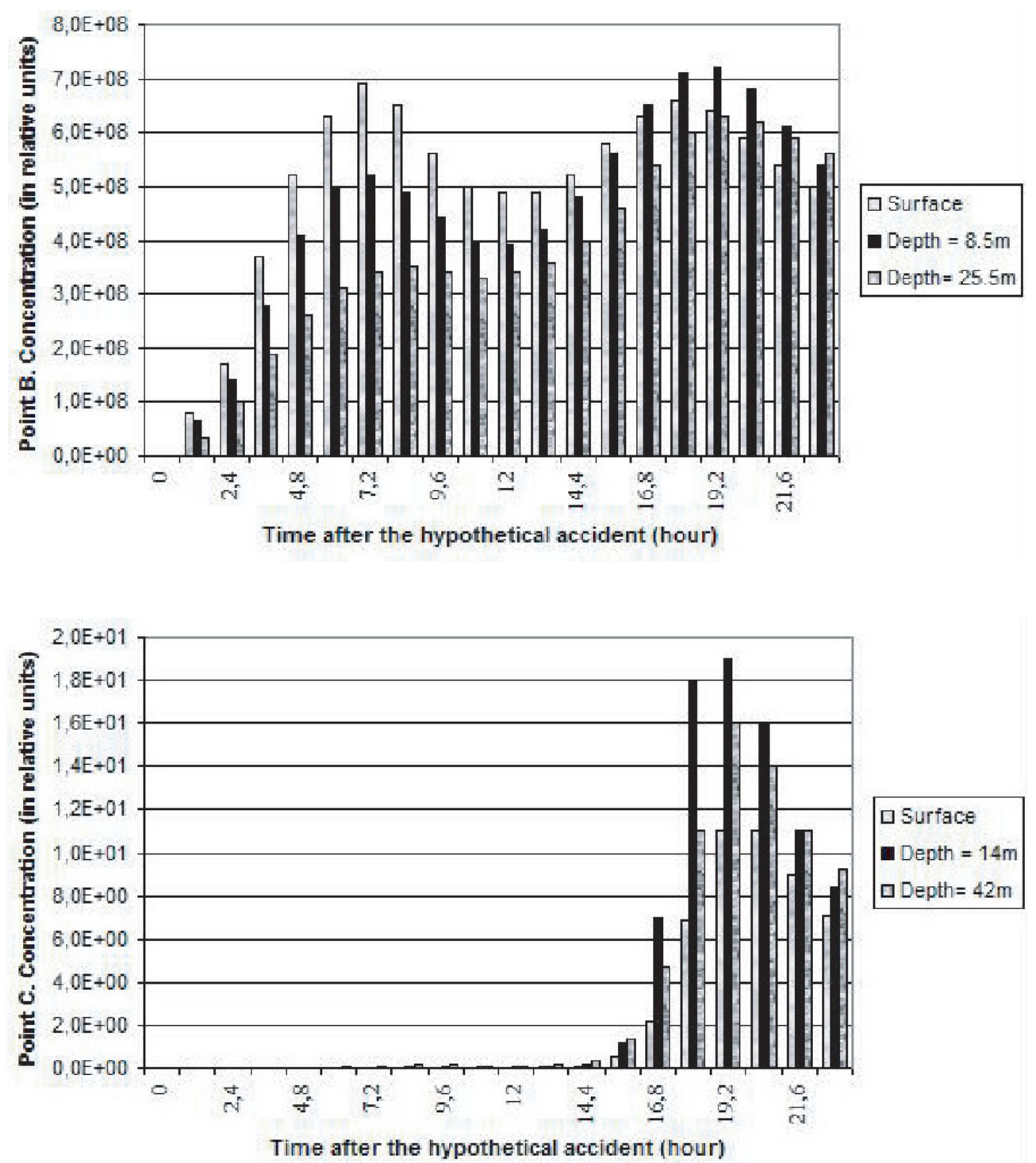

Figure 3. Graph of specific activity after the hypothetical accidental release of radioactive substances at the surface of Saida Bay in the moment of high water (no wind). Point B - 180 meters to north-west from the spot of the accident; point $\mathrm{C}-730$ meters to north-west from the spot of the accident (see Fig. 1).

The examples of calculated isolines of concentration of a radioactive substance (in relative units) in the surface water layer are presented at Fig. 2 for four situations.

One can compare pictures in pares $2 a$ vs. $2 c$ and $2 b$ vs. $2 d$ and see the difference induced by the phase of tide at the moment of hypothetical accident. Comparison of pares $2 \mathrm{a}$ vs. $2 \mathrm{~b}$ and $2 \mathrm{c}$ vs. $2 \mathrm{~d}$ shows the influence of the wind. One can see that a hypothetical accident in the moment of high water results in somewhat wider dispersion of radioactivity than an accident in the moment of low water. But this difference is small in comparison with difference induced by south wind of $10 \mathrm{~m} / \mathrm{s} \mathrm{strength}$. The similar comparisons were done for accidents at other phases of tidal cycle and other wind directions. 
It is interesting to see how concentration of radioactivity varies in time in different locations in the Saida Bay. At Fig. 3 one can see that in both points B and C the concentration at different depth equalize (about 6 hours) very soon after coming of radioactivity. One can also see that in point $\mathrm{B}$ the concentration oscillate with the period of tide and that concentration of radioactivity in point $\mathrm{C}$ in 24 hours after the hypothetical accident remain very small $\left(10^{7}\right.$ times less than in point $\left.B\right)$.

\section{RESULTS AND CONCLUSIONS}

Results of model testing are as follows:

- Strong wind can influence the distribution of the radioactivity in Saida Bay more than any other process;

- The second important process is tidal process especially if in "resonance" currents forced by wind (thus the phase of tidal cycle at the time of accident is very important);

- Most of radioactivity released in the waters of Saida Bay will not live the Bay if the accident will take place at the temporary storage facility of reactor units or near one of the piers were nuclear submarines are stationed.

The check of independence of computation results from computational grid step size was done by comparison results discussed above with the results of computation on the grid with doubled steps. The results of computation on both grids were similar.

It is necessary to emphasize that the aim of the work was not to study the radioecological situation at the Saida Bay itself. The aim was to study applicability of the POM-based model to model migration of radioactivity in the gulfs and bays. The authors conclusion is that modeling results are reasonable and the model is applicable for periods up to several days for radioactive substances that tend to be sorbed by hard particles $\left({ }^{137} \mathrm{Cs}\right.$ for example) and for longer periods for substances that tend to migrate in the solved state $\left({ }^{90} \mathrm{Sr}\right.$ for example).

\section{References}

[1] Amozova L.P., Arutyunyan R.V., Bogatov S.A., Bolshov L.A., Gavrilov S.L, Druzhininsky S.N., Kisselev V.P., Ogar K.V., Ossipiants I.A. and Khandobin V.A., 2007. «Enhancement of the radiation monitoring and emergency response system in the Murmansk region », Proceedings of the Second International Nuclear Forum, St. Petersburg, Russia, 2-5 October 2007.

[2] Mellor, G.L., 2004. Users guide for a three-dimensional, primitive equation, numerical ocean model, Princeton University, http://www.aos.princeton.edu/WWWPUBLIC/htdocs.pom/ FTPbackup/usersguide0604.pdf

[3] Klaus Rotter, 2000. Java-Applets zur Einführung in den Themenkreis Gezeiten für den Physikunterricht, http://www.rotters.de/dl/thesis.pdf

[4] Tide table: Yekaterininskaya $69.2000^{\circ} \mathrm{N}, 33.4667^{\circ} \mathrm{E}$ http://www.mobilegeographics.com:81/ locations/7106.html

[5] http://www.bbc.co.uk/weather/coast/tides/ 
